\title{
ГЕМАТОЛОГИЧЕСКИЕ ПОКАЗАТЕЛИ СИГА ОБЫКНОВЕННОГО (Coregonus lavaretus L.) В УСЛОВИЯХ АНТРОПОГЕННОГО ЗАГРЯЗНЕНИЯ (НА ПРИМЕРЕ ОЗ. КОВДОР)
}

\section{Королева И.М., Терентьев П.М.}

Институт проблем промышленной экологии Севера КНЦ РАH, Anamumbl, koroleva@inep.ksc.ru

Определение гематологических показателей является частью ихтиологической экспертизы, позволяющей оценить физиологическое состояние рыб и проследить наличие и течение патологического процесса. Гематологические показатели изменяются в зависимости от температуры, гидрохимического режима (в том числе от загрязненности воды), состава кормов, сезона года, возраста и могут выступать в качестве специфических маркеров для оценки физиологического состояния организма рыбы.

\section{Материалы и методы}

Полевые работы проводились летом и осенью 2001-2008 гг. в оз. Ковдор, расположенном на западе Мурманской области (рис. 1).

На биологический анализ взято 78 сигов Coregonus lavaretus L., гематологические параметры определены у 30 экземпляров. Отбор крови осуществлялся у свежепойманных (не более 1-1.5 часов после изъятия из воды) рыб из хвостовой вены после отсечения хвоста. Концентрация гемоглобина измерялась в полевых условиях с использованием гемометра Сали. Подсчет эритроцитов велся в камере Горяева. Цитоморфологический анализ выполнялись по мазкам, окрашенным по Романовскому. Оценка состояния периферической крови рыб проводилась по процентному соотношению клеток эритроидного ряда, наличию патологических форм эритроцитов согласно принятым в отечественной гематологии методам [3, 4, 5].

\section{Результаты и их обсуждение}

Озеро Ковдор принадлежит к озерно-речной системе Пиренгских озер, располагающихся на северо-западе водосборного бассейна оз. Имандра, представляет собой озеровидное расширение

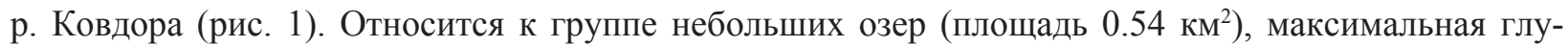
бина 18 м, длина - 1.92 км, ширина от 0.48 км. Территория водосбора относится к лесотундровой зоне с высотами до 453.5 м. Озеро является приемником сточных вод промышленного происхождения («Ковдорский ГОК», занимающийся разработкой месторождения комплексных бадделеитапатит-магнетитовых руд) и хозяйственно-бытовых стоков одноименного города. Известно об аварийном поступлении нефтепродуктов с территории расположенного на его берегу железнодорожного транспортного узла. Вода озера относится к щелочным водам, несмотря на высокие уровни содержания сульфатов (табл. 1). Минерализация воды в оз. Ковдор, как в одном из самых загрязняемых водных объектов, доходит до 619 мг/л, а среднее значение - 233 мг/л. Отмечено высокое со-

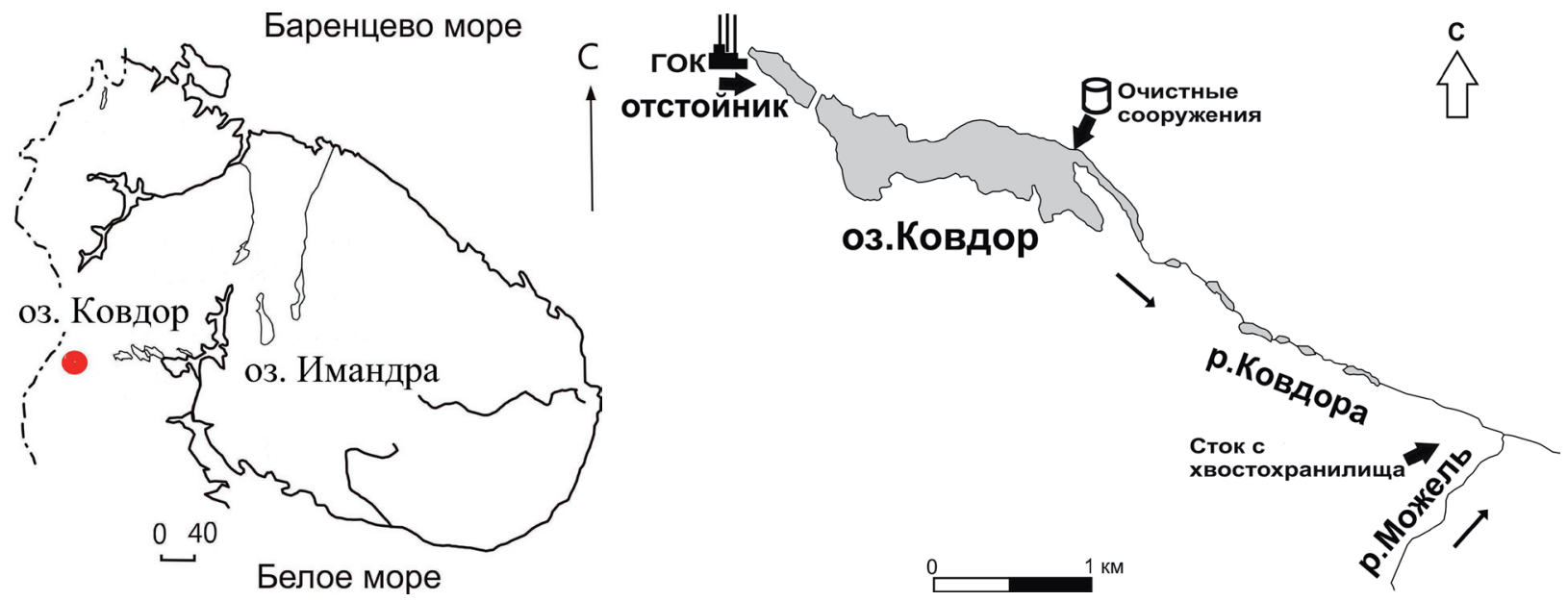

Рис. 1. Карта-схема района исследования. 


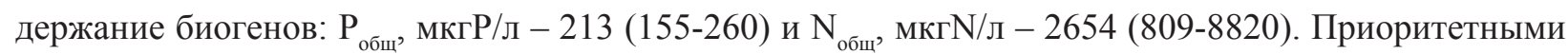
загрязняющими веществами для оз. Ковдор являются соединения тяжелых металлов, Sr, Al, компоненты сточных вод горнорудного производства. Специфическими загрязнителями являются марганец, фосфаты, сульфаты, гидрокарбонаты, взвешенные вещества [1].

Таблица 1. Гидрохимические параметры оз. Ковдор.

\begin{tabular}{|c|c|c|c|c|c|c|c|c|c|}
\hline $\mathrm{pH}$ & $\mathrm{Ca}$, мг/л & $\mathrm{Mg}$, мг/л & $\mathrm{Na}$, мг/л & К, мг/л & $\mathrm{SO}_{4}, \mathrm{Mг} / л$ & $\mathrm{Cl}, \mathrm{мг} /$ л & $\mathrm{Fe}$, мкг/л & Al, мкг/л & $\mathrm{Sr}$, мкг/л \\
\hline$\frac{8.44}{7.16-9.87}$ & $\frac{22.0}{6.02-47.0}$ & $\frac{10.9}{2.71-34.7 .9}$ & $\frac{23.4}{10.1-72.5}$ & 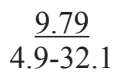 & $\frac{82}{37-270}$ & $2 . \frac{6.6}{9-15}$ & $\frac{103}{25-334}$ & $\frac{92}{11-587}$ & $\frac{1110}{208-3700}$ \\
\hline
\end{tabular}

Сиги были представлены преимущественно малотычинковой формой с числом жаберных тычинок от 16 до 30. Возрастная структура включала 6 групп: от двухлетних до семилетних рыб. Масса сигов в уловах имела широкий предел колебаний от 17 г до 670 г. Высокая доля особей с отложением внутриполостного жира и анализ наполненности желудков свидетельствуют об удовлетворительных условиях нагула рыб. Половое созревание у самцов наступало в трехлетнем возрасте, у самок в четырехлетнем. Более половины особей в октябре имели гонады на IV стадии развития. Наличие готовых к нересту самцов и самок свидетельствует о возможности использовании данного водоема не только для откорма, но и для размножения [2].

Средняя навеска сигов, взятых на гематологический анализ, равнялась 266 г, средний линейный размер $\left(L_{\mathrm{s}}\right)-27.9$ см. Соотношение полов было 1:1.4 с преобладанием самок.

Содержание гемоглобина у сигов из озера было наиболее высоким по сравнению с популяциями из других исследованных нами субарктических водоёмов. Средняя величина уровня гемоглобина составила 120 г/л. Вместе с тем, количество эритроцитов -0.95 млн./мм ${ }^{3}$ и уровень эритропоэза (2.3\% незрелых эритроцитов) близки к показателям, рекомендованным как региональная физиологическая норма [6].

Анализ возрастных изменений гематологических показателей был начат с трехлетнего возраста. Наиболее высокий уровень гемоглобина имели сиги в возрасте $2+-3+$. При наступлении половой зрелости, в нашем случае при достижении пятилетнего возраста, происходит наибольшее падение содержания гемоглобина - с 120 до 105 г/л.

Анализ половых различий в целом подтвердил закономерности, установленные для рыб из других водоемов. У пропускающих нерест самок содержание гемоглобина выше, чем у нерестящихся. Максимальное значение содержания гемоглобина имела четырехлетняя самка массой 230 г - 160 г/л. У нерестовых самок на IV стадии зрелости гонад количество гемоглобина и эритроцитов было самым низким и составляло от 100 до 110 г/л и от 0.82 до 1.1 млн./мм³ соответственно (табл. 2).

Таблица 2. Половые различия характеристик красной крови сига оз. Ковдор (2001-2004 гг.).

\begin{tabular}{|c|c|c|c|}
\hline \multirow{2}{*}{ Показатели } & \multicolumn{3}{|c|}{ Пол, стадия зрелости } \\
\hline & ঐIV & ㅇ II & q IV \\
\hline Гемоглобин (г/л) & $8 \frac{110}{2-140}$ & $\frac{120}{90-160}$ & $\frac{110}{100-110}$ \\
\hline Эритроциты (млн./м³) & $0 . \frac{0.92}{73-1.4}$ & $0 . \frac{0.90}{76-1.7}$ & $0 . \frac{0.82}{82-1.1}$ \\
\hline Количество рыб, экз. & 12 & 15 & 3 \\
\hline
\end{tabular}

Многофакторное загрязнение оз. Ковдор вызвало изменения как количественных гематологических показателей - уровня гемоглобина, содержания форменных элементов крови, процентного соотношения различных групп клеток красной крови, так и качественных - морфологических характеристик и патологических изменений эритроцитов. Превышение уровня содержания гемоглобина у сигов из оз. Ковдор относительно других водоемов позволяет говорить о такой патологии 


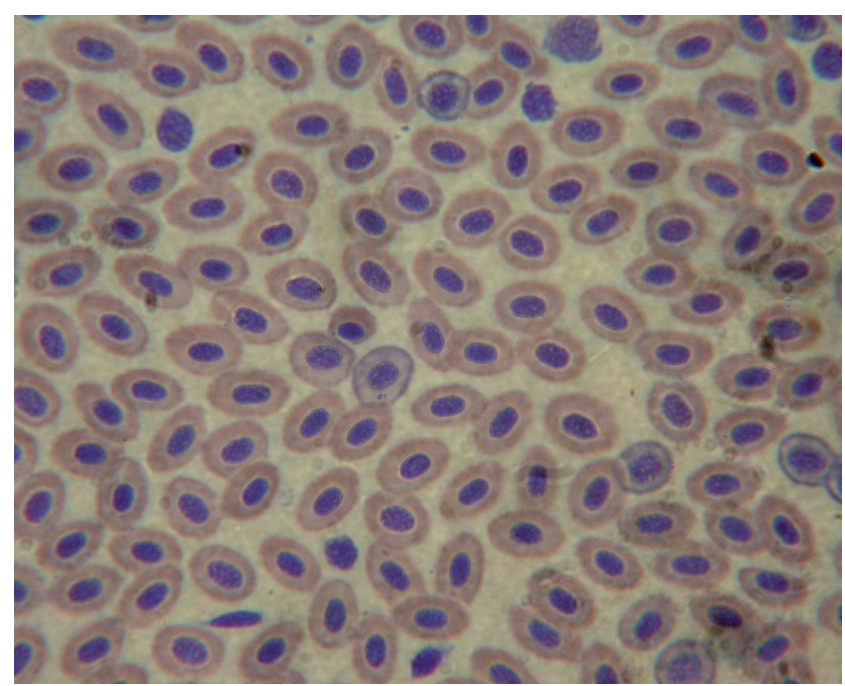

Микроциты, ув. × 1000

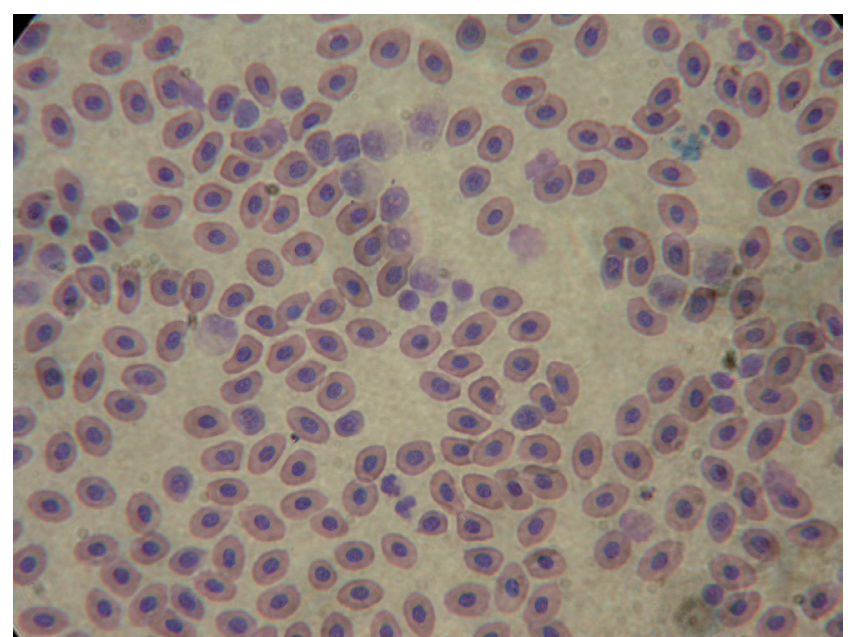

Пойкилоцитоз эритроцитов, ув. × 1000

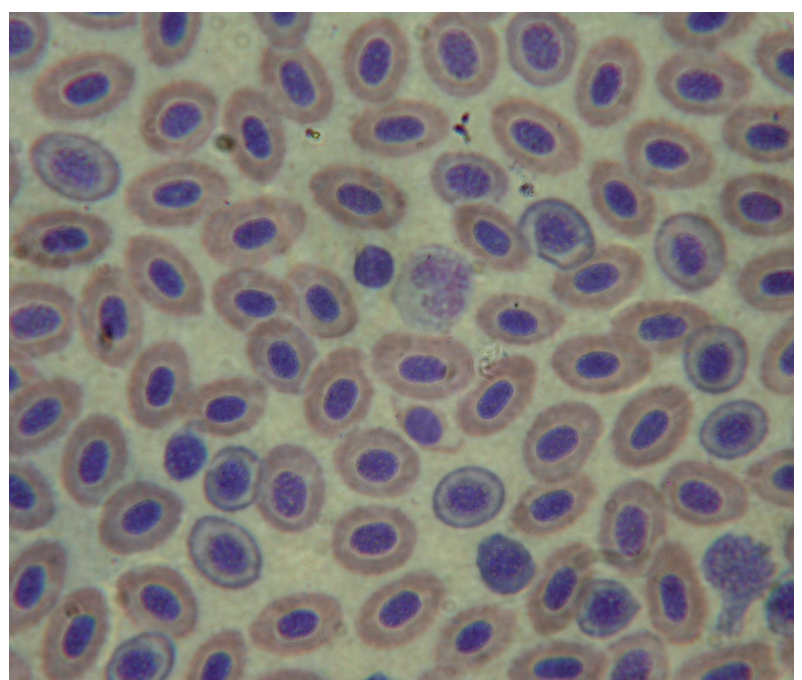

Незрелые эритроциты и анизоциты, ув. × 1000

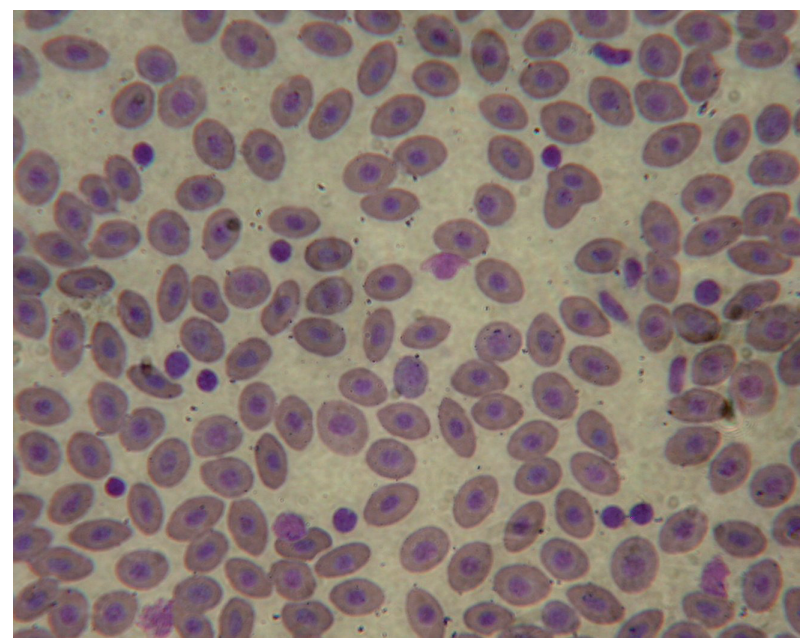

Пикноз ядер эритроцитов, ув. × 1000

Рис. 2. Примеры незрелых и патологических форм эритроцитов.

как «сгущение» крови. Аналогичная картина наблюдалась у сигов из района влияния подогретых вод Кольской АЭС [7].

В условиях загрязнения наблюдалось изменение формы эритроцитов, образование пойкилоцитов - клеток разнообразных, причудливых форм (рис. 2). Подобное дегенеративное явление наступает под влиянием на систему кроветворения разнообразных вредных факторов биологической и химической природы. В оз. Ковдор такими факторами могли выступить стоки Ковдорского горнообогатительного комбината и продукты разложения горюче-смазочных материалов. Клетки измененной формы встречались на мазке крови с частотой до 2.7 \%. Анизоцитоз или разноразмерность считается дегенеративным явлением и говорит о функциональной недостаточности кроветворных органов. Образование микроцитов и шистоцитов вызывается кислородной недостаточностью, усилением обменных процессов или влиянием токсикантов. У рыб из оз. Ковдор анизоциты встречались с частотой 1-3 \%. Из ядерных патологий наблюдался пикноз, который вместе с тем не носил массового характера.

Исследование гематологических показателей адаптации рыб в современных условиях антропогенного воздействия на водоемы позволяет глубже понять уровень и характер воздействия окружающей среды на организм и косвенно определить экологическое состояние водоема. Происходя- 
щие в крови рыб изменения могут служить одним из индикаторов степени токсичности или нетоксичности водной среды. Это дает основание считать ихтиогематологический метод достаточно чувствительным и рекомендовать его для использования как один из элементов в системе комплексного биологического мониторинга водных экосистем.

\section{Выводы}

1. Уровень содержания гемоглобина у сигов из озера Ковдор в среднем равен 115 г/л, количество эритроцитов -0.92 млн/мм³ ${ }^{3}$ Данные показатели несколько выше показателей, установленных как региональная норма для субарктических пресных водоемов.

2. В условиях антропогенной нагрузки у рыб количество незрелых эритроцитов не превышало $3 \%$, что свидетельствует о невысоком уровне интенсивности эритропоэза.

3. Наблюдавшиеся цитопатологии (анизо- и пойкилоцитоз, пикноз ядер) затрагивали небольшое количество эритроцитов и не выходили за границы физиологической нормы, что свидетельствует об удовлетворительных условиях существования рыб в оз. Ковдор.

4. Происходящие в крови рыб изменения могут служить надежным индикатором степени токсичности воды и рекомендуются в качестве биомаркера на клеточном уровне в системе комплексного биологического мониторинга водных экосистем.

\section{Литература}

1. Аннотированный экологический каталог озер Мурманской области: центральный и юго-западный районы Мурманской области (бассейны Баренцева и Белого морей и Ботнического залива Балтийского моря) / Под ред. Н.А. Кашулина. Апатиты: Изд. КНЦ РАН. 2013. Ч. 1. 298 с.

2. Антропогенные изменения лотических экосистем Мурманской области. Ч. 1: Ковдорский район / Под ред. Н.А. Кашулина. Апатиты: Изд. КНЦ РАН. 2005. 234 с.

3. Голодец Г.Г. Лабораторный практикум по физиологии рыб. М.: Пищепромиздат, 1955.90 c.

4. Иванова Н.Т. Атлас клеток крови рыб. М.: Легкая и пищевая промышленность, 1983. 184 с.

5. Инструкция по физиолого-биохимическим анализам рыбы. М.: Изд-во ВНИИРХ, 1986. 53 с.

6. Королева И.М. Гематологические показатели сига обыкновенного Coregonus lavaretus в водоёмах Кольского севера // Тр. ВНИРО. 2016. Т. 162. С. 37-46.

7. Моисеенко Т.И. Теоретические основы нормирования антропогенных нагрузок на водоемы Субарктики. Апатиты: Изд. КНЦ РАН. 1997. 261 с. 